\title{
Partial biliary obstruction with cholangitis producing a blind loop syndrome
}

\author{
A. J. SCOTT AND G. A. KHAN \\ From the Departments of Medicine and Microbiology, Royal Free Hospital, London
}

The frequency with which bacterial cholangitis complicates choledocholithiasis or benign postoperative biliary strictures has been the subject of several studies (Elkeles and Mirizzi, 1942; Anderson and Priestley, 1951; Edlund, Mollstedt, and Ouchterlony, 1959; Scott and Khan, 1967). The magnitude of the bacterial population present in this condition had, however, been crudely assessed until in a recent study it was shown that quantitatively the bacterial population of an infected bile duct per gram of contents rivalled that of the colon as far as aerobic organisms were concerned (Scott and Khan, 1967). It therefore seemed possible that as bacteria multiplied in bile and as the heavily infected bile was secreted into the intestine functional changes would be produced which would parallel those which follow infestation of the small bowel in the 'blind loop syndrome'. In this paper we are reporting a study of 11 patients with partial biliary obstruction and cholangitis. We have employed techniques of investigation which have proved helpful in understanding the typical blind loop syndrome and have obtained results that suggest that such a parallel situation may indeed be present.

\section{METHODS}

Eleven patients were studied both before and during surgery. Five of these had calculous cholecystitis and choledocholithiasis. One patient had choledocholithiasis which had been previously treated by a cholecyst-duodenostomy. The other five patients had benign postoperative strictures involving hepatodochojejunostomy anastomoses. The anatomical features in the 11 patients are summarized in Figure 1. All were jaundiced, with serum bilirubin values ranging up to $14 \mathrm{mg} \%$, and all had had attacks of clinical cholangitis. These were recurrent at the time of study in all but one. Two only had received antibiotic treatment in the six weeks that preceded the study.

Bile was obtained at operation by aspirating the contents of the common bile duct or common hepatic duct. Intestinal contents were obtained either preoperatively by oral intubation with a narrow bore tube (Kalser, Cohen, Arteaga, Yawn, Mayoral, Hoffert, and Frazier, 1966) in the patients with bile draining into the duodenum,

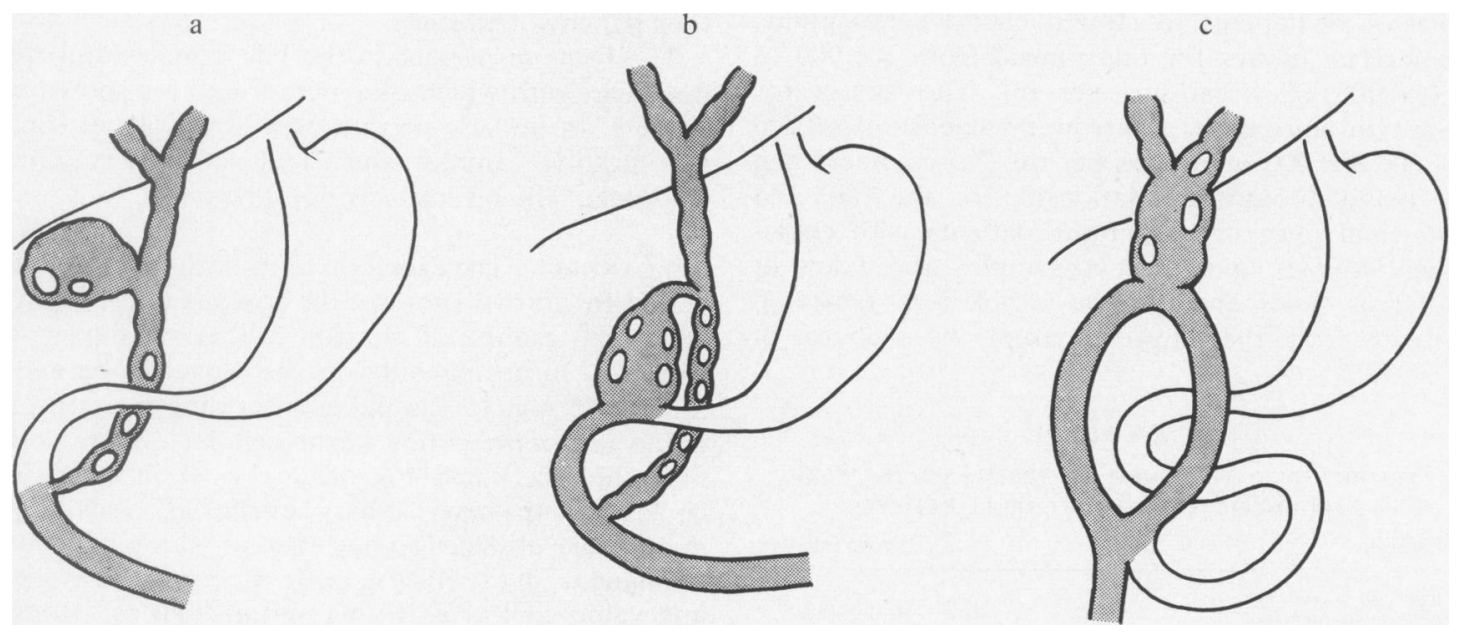

FIG. 1. The anatomical features in the 11 patients studied. five with choledocholithiasis (a); one with cholecystduodenostomy (b); and five with hepatodochojejunostomy and enteroanastomosis (c). 
or during the operation by passing a Levine tube into the jejunum during the reconstruction of the hepatodochojejunostomy anastomoses in the five patients with benign strictures. Bile and intestinal contents were immediately cultured on $10 \%$ blood and McConkey's agar aerobically and anaerobically and viable bacterial counts were performed by the method of Miles and Misra (1938).

Urine indican was measured by the method of Curzon and Walsh (1962). Thin-layer chromatography plates were prepared by standard techniques (Hofmann, 1964) and in particular the development systems described by Hofmann (1962) and by Gregg (1966) were used. Bile salts were detected by spraying the plates with $10 \%$ molybdophosphoric acid in ethyl alcohol or 1:1 methanol/ concentrated sulphuric acid and identified by reference to the mobility of standard substances after one- or two-dimensional development. Vitamin $B_{12}$ absorption was detected by a standard tracer technique (Schilling test) using $0.5 \mu \mathrm{g}$ vitamin $\mathrm{B}_{12}-\mathrm{Co}_{58}$ orally and $1 \mathrm{mg}$ stable vitamin $B_{12}$ intramuscularly, with the urinary radioactivity in the first $\mathbf{2 4}$ hours expressed as a percentage of the oral dose (normal greater than $12 \%$ ). Hog intrinsic factor, $50 \mathrm{mg}$, was given with the oral dose. In six patients the test was repeated after tetracycline, $1 \mathrm{~g}$ daily, had been given for the preceding three days.

To exclude the possibility that an abnormality might have been due to biliary obstruction or parenchymal liver disease per se urine indican was also measured in six patients with obstructive jaundice due to pancreatic cancers who had sterile bile and 14 patients with cryptogenic or primary biliary cirrhosis. For the same reason the bile of 19 patients with pancreatic or biliary cancers and obstructive jaundice, in whom the bile was free of bacteria, was examined by thin-layer chromatography.

\section{RESULTS}

BACTERIOLOGICAL FINDINGS In Fig. 2 the concentrations of viable bacteria in the bile and intestinal juice of the patients are plotted against a logarithmic scale. The figures for bile ranged from 100,000 to $7,000,000,000$ organisms per $\mathrm{ml}$. The figures for intestinal juice cover a narrower range from 700,000 to $200,000,000$ organisms per $\mathrm{ml}$. No comment can be made about the relationship of the bile and intestinal juice figures in the patients with choledocholithiasis since the two samples were taken at different times and the bile sample was separated in time from the intestinal sample by a course of

\section{TABLE I}

FREQUENCY WITH WHICH BACTERIAL SPECIES WERE ENCOUNTERED IN THE BILE OF 11 PATIENTS

No. of Isolations

Escherischia coli

Klebsiella aerogenes

Streptococcus faecalis

Proteus vulgaris

Pseudomonas aeruginosa

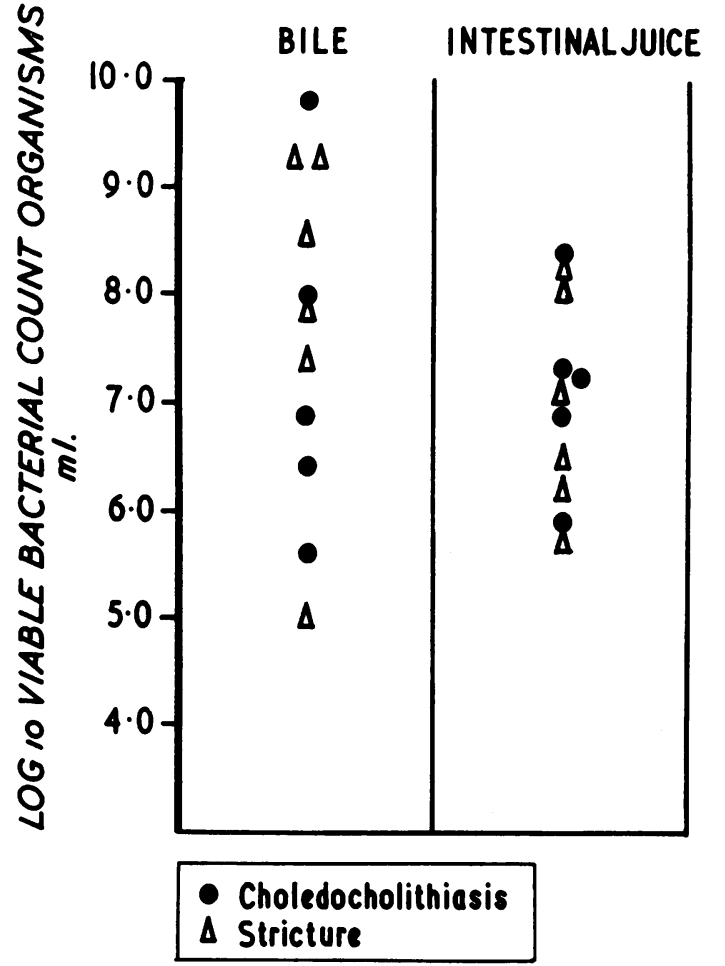

FIG. 2. The concentrations of viable bacteria in bile and intestinal contents plotted against a logarithmic scale. The patient with the cholecyst-duodenostomy is included among the patients with strictures.

antibiotic treatment. In the other six patients the concentration of organisms in two was greater in the intestine than in the bile while in the remaining four patients it was less.

The bacteria present in the bile samples and the frequency with which they were found are shown in Table I. In no case was an organism isolated from the intestinal samples which had not been cultured from bile. The reverse was not always so, however.

INDICANURIA The excretion of indican in a 24-hour period by normal subjects, the patients under study, and three groups of control patients is shown in Figure 3. In normal subjects the range lay between 35 and $75 \mathrm{mg}$. In the patients forming the control group and representing hepatocellular disease with little cholestasis (cryptogenic cirrhosis), intrahepatic cholestasis (primary biliary cirrhosis), and large duct biliary obstruction but with no biliary infection (malignant duct obstruction), the range is wider and values as low as $10 \mathrm{mg}$ and as high as $110 \mathrm{mg}$ were found. Of the nine patients with infected bile in whom $E$. coli was found in the bile and intestinal 


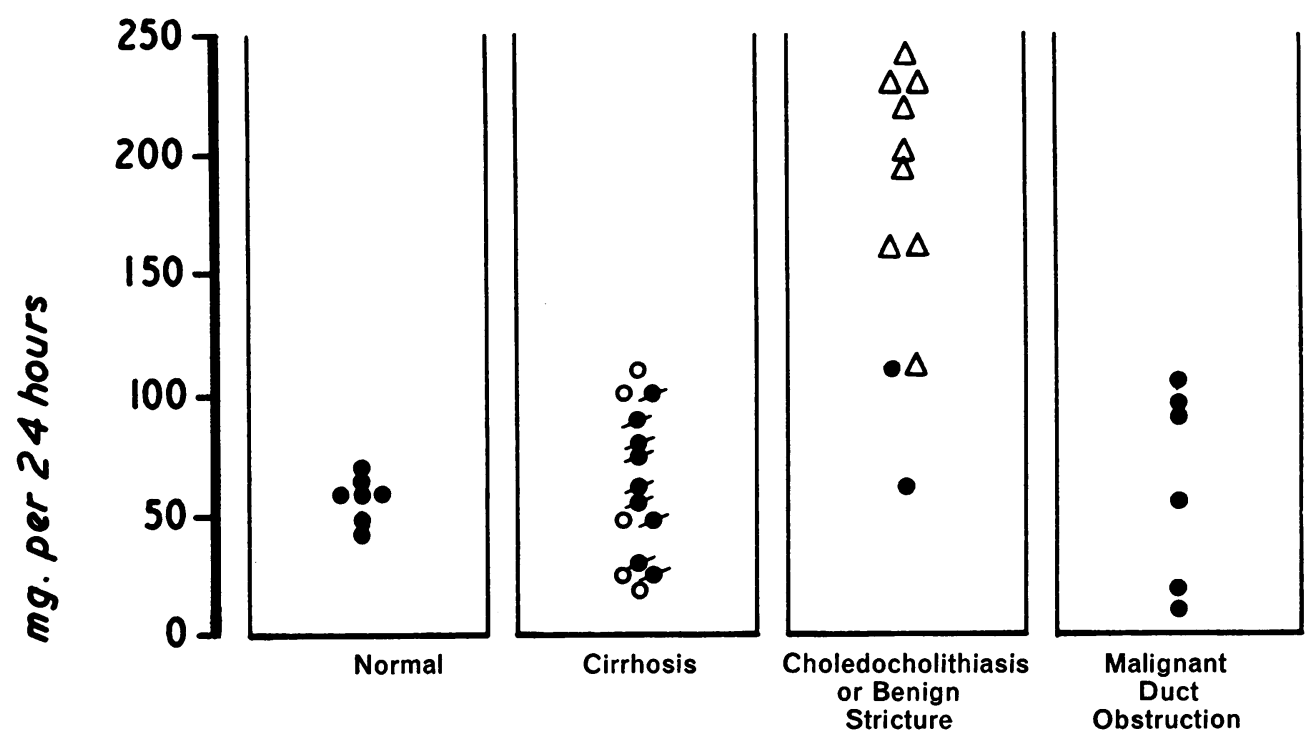

\section{Cryptogenic - Primary Biliary $\Delta$ E.coli in bile}

juice, eight showed increases in urinary indican beyond this range. $E$. coli was the only indoleproducing organism isolated in this group.

BILE ACIDS Unconjugated bile acids were not found in the sterile bile of the 19 patients with large duct biliary obstruction due to cancers. Unconjugated bile acids were, however, present in six of the 11 patients with biliary infection. Two of these were patients with choledocholithiasis, three had strictures, and one was the patient previously treated by cholecystduodenostomy. The chromato-

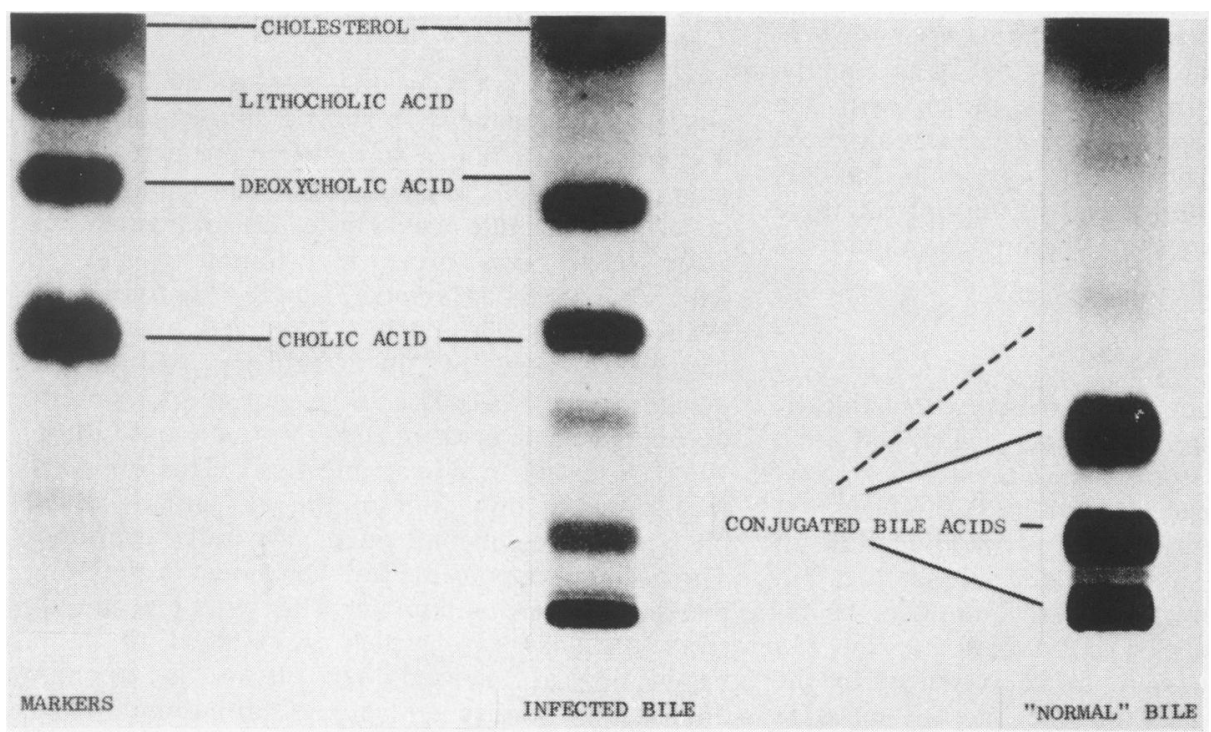

FIG. 4. Thin-layer chromatogram of bile acids. The infected bile was from the patient with a cholecystduodenostomy. The 'normal' bile was from a patient with carcinoma of the head of the pancreas and biliary obstruction but sterile bile. The development system is that of Gregg (1966) and the bile acids have been detected with $10 \%$ molybdophosphoric acid in ethanol. 


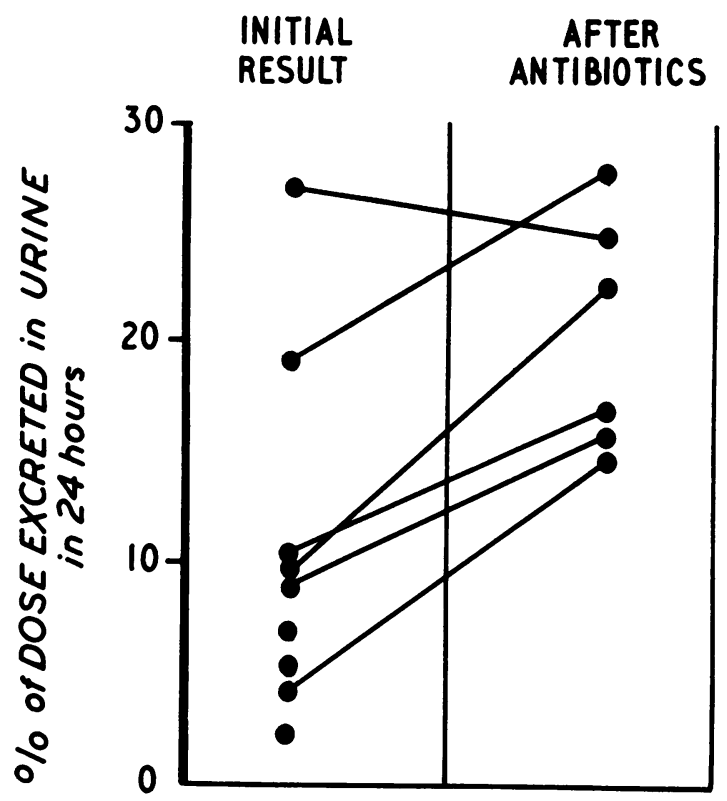

FIG. 5. Vitamin $B_{12}$ absorption measured by the Schilling technique. Normal value greater than $12 \%$.

gram from this patient is shown in Figure 3. It shows the most common finding with cholic acid and chenodeoxycholic acid present in unconjugated form. Unconjugated secondary bile acids (deoxycholic and lithocholic acids) were found in only one patient. Unconjugated acids were only found when biliary 'sand' or 'mud' was present in the sample.

VITAMIN $B_{12}$ In two patients the Schilling test result was unreliable for technical reasons. The results in the remaining nine patients are shown in Figure 5. Two patients had normal values in the initial test. One of these was the patient with the cholecyst-duodenostomy and the other was a patient with a stricture. The remaining seven patients showed subnormal values and in the four of these tested following tetracycline therapy the value rose into the normal range.

\section{DISCUSSION}

The classical blind loop syndrome presents clinically with malnutrition, vitamin $B_{12}$ deficiency, and often diarrhoea or bulky stools. The salient biochemical features are steatorrhoea, vitamin $\mathbf{B}_{12}$ malabsorption, indicanuria, and variable deconjugation of bile acids within the small bowel. These features can all be related to abnormally large numbers of microorganisms in some part of the small intestine. If a comparable situation were to be produced by the secretion of heavily infected bile into the intestine then one might expect these features to be indentifiable in patients in whom it occurs. Now patients with partial biliary obstruction and cholangitis frequently do lose weight rapidly but it is difficult to assign the responsibility to such a mechanism when such other factors as infection and biliary obstruction are also present. Steatorrhoea is common to both conditions but it too has an ambiguous significance. And since jaundice draws early attention to the biliary obstruction the condition will never be present for long enough for overt vitamin $B_{12}$ deficiency to appear. We have therefore confined our attention to those remaining features which seem relatively unambiguous in their interpretation.

It was first necessary to establish that bacterial contamination of the small bowel could reach significant levels. Elkeles and Mirizzi (1942) had reported that culture of duodenal contents resulted in a heavy growth of bacteria when bacterial cholangitis was present suggesting that this would prove to be the case. And indeed in the 11 patients we studied the values obtained for the concentration of viable bacteria in intestinal contents are in the range found by Tabaqchali, Okubadejo, Neale, and Booth (1966) in patients with the blind loop syndrome. Furthermore, the species of bacteria cultured are similar to those isolated in that study and the incidence with which the various organisms were found to occur follows the same pattern. In the special situation with which we were dealing effects mediated by bacteria might then be expected to occur to the constituents of bile and to substances present in the small intestine. Alterations to bile acids can be taken as an example of the first kind of effect while indicanuria and vitamin $B_{12}$ malabsorption would result from effects occurring in the intestine.

Normal bile contains only conjugated bile acids and that this remains so during simple cholestasis is shown by our failure to find free bile acids where jaundice was due to malignant obstruction of the ducts and the bile was sterile. Unconjugated bile acids have been previously found in patients with cholangitis (Hansson, Lundh, Stenram, and Wallerström, 1963) and this is scarcely a surprising finding in view of the frequency with which Streptococcus faecalis, an organism known to deconjugate bile acids in vitro (Norman and Grubb, 1955), is found in biliary infections. This organism was present in only four of the six patients whose bile contained unconjugated bile salts, however. The bacteria responsible for the change in the other two patients are unknown. This provides a difficulty, the answer to which is assumed to lie in bacteriological methodology. It is a common difficulty in studies on patients with blind loops, 
however, as can, for example, be seen from the data of Tabaqchali and Booth (1966).

If bacteria in the obstructed bile duct can deconjugate bile acids it must be expected that alterations in other important constituents of bile will also be produced. $E$. coli produces a $\beta$-glucuronidase which might be expected to deconjugate bilirubin glucuronides, and Maki (1966) has implicated this bacterial effect in the pathogenesis of the common Asian calcium bilirubinate gallstones. Other similar effects must remain to be described.

Indican in urine provides a measure of the production of indole in the intestine, and it is related therefore to the intake of dietary tryptophan and the presence of indole-producing bacteria in the intestine (Bryan, 1966). It is consequently excreted in excess in patients with the blind loop syndrome in whom indole-producing organisms are in contact with a major part of the dietary tryptophan and in these patients it has been proposed as an 'indirect measure of the presence of coliform bacteria in the small gut' (Tabaqchali et al., 1966). In the patients we studied increased levels of urinary indican were present in all those patients in whom $E$. coli was present in the bile. Minor increases in urinary indican were also seen in patients with hepatocellular liver disease, intrahepatic cholestasis, and large duct biliary obstruction but without cholangitis. Explanations for these smaller increases are not difficult to find in terms of the increased ileal colonization with bacteria that has been seen in the cirrhotic patient (Martini, Phear, Ruebner, and Sherlock, 1957) and of the protein maldigestion that is present in pancreatic exocrine failure. The considerably greater increases in the patients with cholangitis leave no doubt that they are directly related to the abnormal jejunal flora derived from the infected biliary system rather than to cholestasis and the concomitant steatorrhoea per se. The reversal of vitamin $B_{12}$ malabsorption following the administration of tetracycline similarly implicates an abnormal intestinal flora.

It therefore seems reasonable to draw a parallel between the classical blind loop syndrome and the situation that results when heavily infected bile is secreted into the intestine-what might be called a 'stagnant bile' syndrome. The clinical significance of the parallel is conjectural. Perhaps it does help to explain the at times dramatic weight loss of the patient with cholangitis. Possibly it will help to explain the relatively unsatisfactory results of biliary bypass surgery in patients with established biliary infections. It is most unlikely to help in diagnosis in other than the very occasional patient since the difficult to diagnose silent stone is unlikely to be producing sufficient obstruction for the neces- sary heavy infection of bile that underlies the syndrome.

However, the realization that the biliary system, if the seat of rapid bacterial proliferation, may determine changes which may greatly distort the enterohepatic circulation of substances excreted in the bile, is in itself of some importance. Variations in the enterohepatic circulation can produce marked variations in the composition of bile, and it is conceivable that abnormalities in this circulation might underlie those minor alterations in bile composition that have been found in lithiasic bile. Certainly in an experimental animal it has been possible to prevent gallstone formation by what has been interpreted as an alteration in the bacterial component of the enterohepatic circulation (Schoenfield and Sjövall, 1966). Schoenfield, Sjövall, and Sjövall (1966) have also suggested that the bile acid composition of the centres of human gallstones would provide evidence of an abnormality in the enterohepatic circulation of bile acids at the time the stone was forming. It is therefore possible that the observations that we have made may help to unify what have hitherto appeared to be opposed views of the roles of bacterial infection and diet or constitutional factors in the production of gallstones.

\section{SUMMARY}

Eleven patients with partial biliary obstruction and bacterial cholangitis have been studied in an attempt to define the role of the bacteria which are rapidly multiplying in their bile ducts. The condition has been shown to result in significant soiling of the small bowel and in abnormalities in tryptophan metabolism, bile acid metabolism, and vitamin $\mathbf{B}_{12}$ absorption. A parallel has therefore been drawn between this situation and that seen in the blind loop syndrome'.

We would like to thank Miss P. George for her help in providing the surgical specimens, and $\mathrm{Mr}$. $\mathrm{H}$. Williams and his Department for the work involved in the Schilling tests. A.J.S. was supported by a Nuffield Foundation Fellowship. G.A.K. was supported by a grant from Lepetit S.p.a., Milan.

\section{REFERENCES}

\footnotetext{
Anderson, R. E., and Priestley, J. T. (1951). Observations on the bacteriology of choledochal bile. Ann. Surg., 133, 486-489.

Bryan, G. T. (1966). Quantitative studies on the urinary excretion of indoxyl sulfate (indican) in man following administration of $\mathrm{L}$ tryptophan and acetyl-L-tryptophan. Amer. J. clin. Nutr. $19,105-112$.

Curzon, G., and Walsh, J. (1962). A method for the determination of urinary indoxyl sulphate (indican). Clin. chim. Acta, 7, 657-663.
} 
Edlund, Y. A., Mollstedt, B. O., and Ouchterlony, Ö. (1959). Bacteriological investigation of the biliary system and liver in biliary tract disease correlated to clinical data and microstructure of the gallbladder and liver. Acta chir. scand., 116, 461-476.

Elkeles, G., and Mirizzi, P. L. (1942). A study of the bacteriology of the common bile duct in comparison with the other extrahepatic segments of the biliary tract. Ann. Surg., 116, 360-366.

Gregg, J. A. (1966). New solvent systems for thin-layer chromatography of bile acids. J. Lipid Res., 7, 579-581.

Hansson, K., Lundh, G., Stenram, U., and Wallerström, A. (1963). Pancreatitis and free bile acids. Acta chir. scand., 126, 338-345.

Hofmann, A. F. (1962). Thin layer absorption chromatography of free and conjugated bile acids on silicic acid. J. Lipid Res., 3, $127-128$.

- (1964). Thin layer chromatography of bile acids and their derivatives. In New Biochemical Separations, edited by A. T. James and L. J. Morris, p. 261. Van Nostrand, London.

Kalser, M. H., Cohen, R., Arteaga, I., Yawn, E., Mayoral, L., Hoffert, W. R., and Frazier, D. (1966). Normal viral and bacterial flora of the human small and large intestine. New Engl. J. Med., 274, 500-505, 558-563.
Maki, T. (1966). Pathogenesis of calcium bilirubinate gallstone. Ann. Surg., 164, 90-100.

Martini, G. A., Phear, E. A., Ruebner, B., and Sherlock, S. (1957). The bacterial content of the small intestine in normal and cirrhotic subjects: relation to methionine toxicity. Clin. Sci., 16, 35-51.

Miles, A. A., and Misra, S. S. (1938). The estimation of the bactericidal power of the blood. J. Hyg.(Lond.), 38, 732-749.

Norman, A., and Grubb, R. (1955). Hydrolysis of conjugated bile acids by Clostridia and enterococci. Acta path. microbiol. scand., 36, 537-547.

Schoenfield, L. J., and Sjövall, J. (1966). Bile acids and cholesterol in the bile of guinea pigs with induced gallstones (Abstr). $J$. clin. Invest., 45, 1071.

- - _ - and Sjövall K. (1966). Bile acid composition of gallstones from man. J. Lab. clin. Med., 68, 186-194.

Scott, A. J., and Khan, G. A. (1967). Origin of bacteria in bileduct bile. Lancet, 2, 790-792.

Tabaqchali, S., and Booth, C. C. (1966). Jejunal bacteriology and bile-salt metabolism in patients with intestinal malabsorption. Ibid., 2, 12-15.

_-, Okubadejo, O. A., Neale, G., and Booth, C. C. (1966). Influence of abnormal bacterial flora on small intestinal function. Proc. roy. Soc. Med., 59, 1244-1246. 